\title{
XXIV. Description of a hydrostatic balance, by which the specific gravities of minerals may be ascertained without calculation. Read June 16, 1818
}

\author{
Benj. H. Coates M.D.
}

To cite this article: Benj. H. Coates M.D. (1821) XXIV. Description of a hydrostatic balance, by which the specific gravities of minerals may be ascertained without calculation. Read June 16, 1818, Philosophical Magazine Series 1, 58:280, 109-110, DOI: 10.1080/14786442108652580

To link to this article: http://dx.doi.org/10.1080/14786442108652580

曲 Published online: 29 Jul 2009.

16 Submit your article to this journal $\sqsubset$

Џll Article views: 2

Q View related articles $\llbracket$ 
of the first. The larger pea will then indicate the mits of weight, and the smaller the tenths or hundredths. The same object might also be obtained by suspending the pea to the middle of a Vernier-scale.

The instrument, and its necessary appendages, are arranged in a small box, so as to be very convenient, and very portable.

Your Committee, after a due consideration and an actual trial of this apparatus, are of opinion, that, for facility and rapidity of operation, it has the advantage over every other that has hitherto been proposed for the same purpose; and they therefore cheerfully recommend it to the attention of the Academy.

They propose that it should be named Lukens's Hydrostatic Balance.

All which is respectfully submitted.

William Maclure.

R. M. Patterson.

ISAAC LEA.

XXIV. Description of a Hydrostatic Balance, by which the Specific Gravities of Minerals may be ascertained without Calculation. By Bens. H. Coates, M.D. Read June 16, 1818*.

$\mathbf{T}$

H E present instrument (see Plate II. fig. 2,) has arisen from one lately presented to the Academy, in which the common steelyard is employed for this purpose.

The object of the alteration is, without rendering the instrument more complicated, or more troublesome in its application, to save the labour and inconvenience of calculation. By means of it, the specific gravity of a mineral may be ascertained in a few moments, and without pen and ink, or any other assistance than a cup of water. With the aid of the neatness and convenience of the instrument on which it is grafted, it is hoped to be a practical saving of time and labour to the mineralogist.

The lever resembles that of a common steelyard, and is contrived to balance exactly, by making the shorter end wider, and with an enlargement at the extremity. The upper edge of each limb is rectilinear, and free from notches, for the sake of accuracy in adjusting the weights.

The shorter end is undivided; but on the longer is inscribed a scale, of which every division, reckoning from the extremity of the lever, is marked with a number, which is the quotient of the length of the whole scale, divided by the distance of the division from the end. Thus, at half the length is marked the number 2 ,

* From the Journal of the Academy of Natural Sciences of Philadelphia, Vol. I. Part II. 


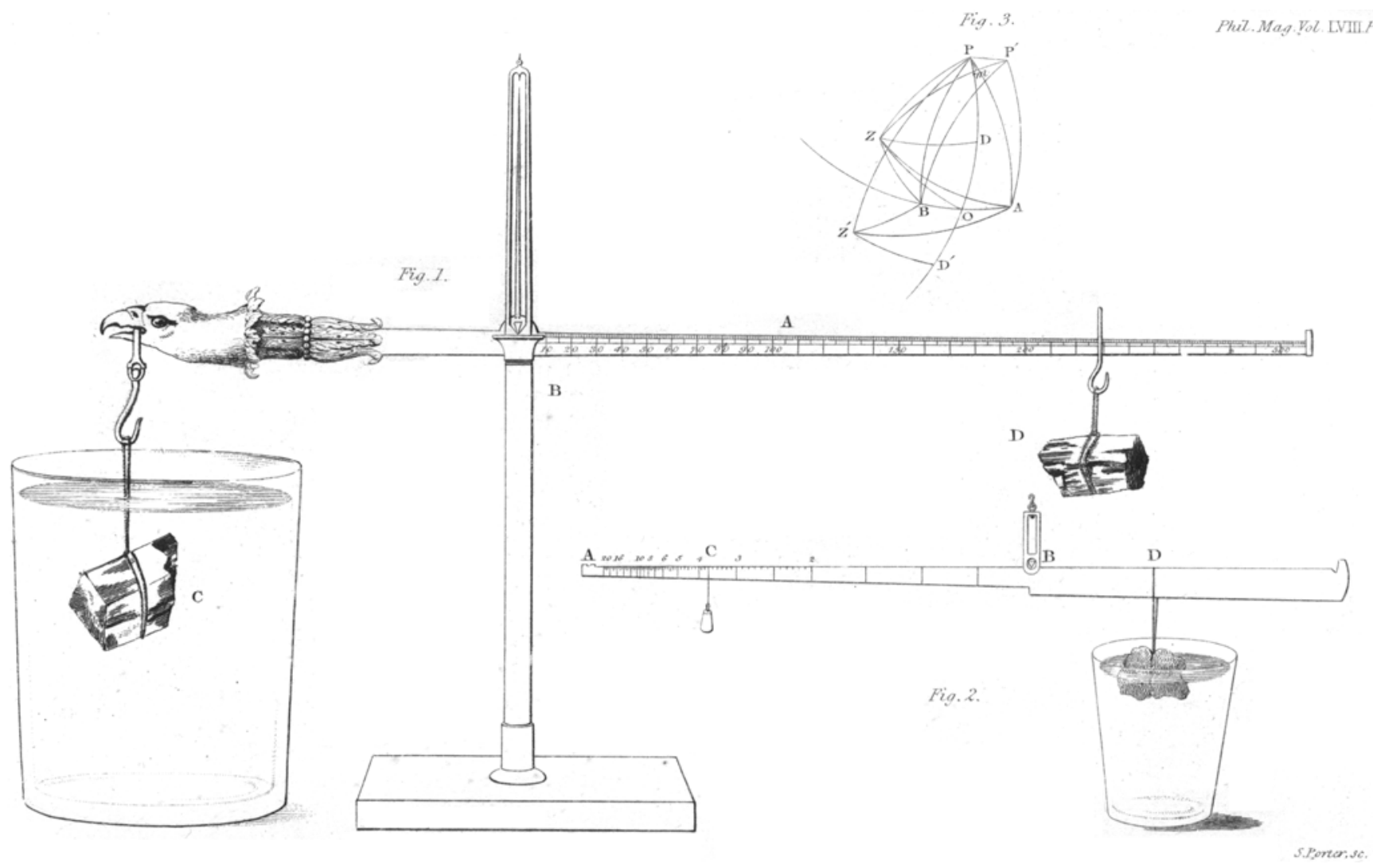


at one-third, 3, at one-fourth, 4, \&c. Also at two-thirds the length is marked $1 \frac{1}{2}$, at two-fifths, $2 \frac{1}{2}$, \&c. And so of all the fractions, sufficiently minutely. These numbers extend as high as the specific gravity of platina;-the pivot of the instrument represents unity, and a notch is made at the further end.

In using this instrument, any convenient weight is suspended by a hook from the notch at the end of the scale. The body under examination is to be suspended to the other end by a horsehair, and slid along till an equilibrium is produced. It is then, without altering its situation on the beam, to be immersed in water, and baianced a second time by sliding the weight. The hook of the latter then marks the specific gravity on the scale.

The demonstration of this is very simple. 'The instrument' being supposed in equilibrium, and $\mathrm{BD}$ (see figure) and the weight of the counterpoise being constant, the weight of the body varies as the distance of the counterpoise from $B$, by the common principle of the lever. Hence, if $\mathrm{C}$ be the place of the weight at the conclusion of the operation,

Weight in water : weight in air : : B C : B A. And, by subtraction, the loss of weight in water : weight in air : : $A C: A B$; and hence

$\frac{\text { wt. in air }}{\text { loss }}=\frac{A B}{A C}=$ the spec. grav.; which is the rule. a. E. D.

Substances lighter than water may have, if necessary, their specific gravity ascertained by the usual method; a scale of equal parts being cut on the opposite side of the beam, and the article to be weighed placed in a notch for the purpose. For mineralogy, however, this will seldom be necessary. The bottom of the notch A (at the sinaller end) should be in a line with the edge of the scale, its sides being a little raised. The top of the shorter end should be rather the thickest part of it, to allow the horse-hair, by which the mineral is suspended, to swing clear. This mode will be found very delicate and accurate, and a hook must not be used, as it cannot be balanced.

The instrument, in this form, is exceedingly compact, and may be reduced to a simple rod.

The principle is capable of being applied (as in an instrument I have made) to an arc of a circle, with a rod resembling in its application a common bent lever.

XXV. True apparent Right Ascension of Dr. Maskelyne's 36 Stars for every Day in the Year 1821. By the Rev. J. GroobY.

[Continued from p. 52.] 